\title{
The role of social class on health behaviors and psychosocial factors: the United States experience
}

\author{
Dr. Borrell is an assistent professor at the Department of Epidemiology, Mailman School of Public Health, \\ Columbia University, New York, USA
}

Published Online First: 21 July 2005

De Vogli et al. (2005) suggest that cigarette smoking, binge drinking and fruit and vegetable consumption are not associated with social class regardless of gender. However, physical inactivity was significantly associated with social class in both males and females. Although, physical inactivity increases as social class decreases, this association was not linear. Social class was not associated with stress. The article also shows that stress was significantly associated with smoking, low consumption of fruits and vegetables and physical inactivity in both males and females. Lack of emotional support was associated with smoking and low fruit and vegetable intake in men, and with physical inactivity in both men and women. The authors suggest that the failure to detect an association between social class and health behaviors, although surprising, could be attributed to the socio-economic climate of the study site; an incomplete epidemiological transition with regard to health behaviors and social class; and the lack of successful interventions to increase the adoption of healthy behaviors in Veneto. In the United States (US), health behaviors are associated with racelethnicity, and further, with socio-economic status (SES), two strong predictors of social inequality in the US. In addition, health behaviors also are linked to stress. For example, smoking is associated with education: People with less than a high school diploma tend to smoke more than those with a high school diploma or more regardless of gender (National Center for Health Statistics 2004). This linear pattern is consistent regardless of racelethnicity. However, minority groups (i. e. African Americans and Hispanics) bear higher prevalence at lower levels of education when compared to their counterparts and to whites. For example, African American men $(38.1 \%)$ and women $(28.5 \%)$ with less than a high school diploma are more likely to smoke than their counterparts with more than a high school diploma (19.4\% and $16.0 \%$, respectively). It is possible that in Italy, and most specifically in the Veneto region, although social class differences exist, they are not as striking as in the US, and, therefore, their impact on health behaviors, stress and social support is lessened.

Several studies have found an association between stress and smoking in the US (Beech et al. 2003; Kassel 2000; Liu 2003; Siqueira et al. 2001; Todd 2004; Wills et al. 2002), with smoking acting as a buffer to cope with daily stressful situations. This association has been observed in several minority groups and appears to depend on SES. For example, African Americans, and more specifically those with low SES, are more likely to smoke but they also are more likely to be exposed to stressful situations (i. e. neighborhood environment, working conditions and racial discrimination) (Massey 2001; Williams \& Collins 1995; Williams 1998, 1999). Thus, the US experience suggests that stress could mediate the association between social class and health behaviors. It is possible that the association between health behaviors and stress reported by De Vogli et al. could have persisted after adjusting for lack of social support and social class or that an association between health behaviors and social class could have emerged after adjusting for stress and lack of social support. De Vogli and colleagues need to be commended for taking on this important area of research in an area with low income inequality. Their findings could help elucidate some of the unanswered questions and motivate new questions in this research area.

Luisa N. Borrell

Soz.- Präventivmed. 50 (2005) 193-194 


\section{References}

Beech BM, Scarinci IC (2003). Smoking attitudes and practices among low-income AfricanAmericans: qualitative assessment of contributing factors. Am J Health Promot 17: 240-8.

De Vogli R, Gnesotto R, Goldstein M, Andersen $R$, Cornia GA (2005). The lack of social gradient of health behaviors and psychosocial factors in Northern Italy. Soz Praventiv Med 50: 197-205.

Kassel JD (2000). Smoking and stress: correlation, causation, and context. Am Psychol 55: $1155-6$.

Liи X (2003). Cigarette smoking, life stress, and behavioral problems in Chinese adolescents. J Adolesc Health 33: 189-92.

Massey DS (2001). Residential segregation and neighborhood conditions in US metropolitan areas. In: Smelser N, Wilson WJ, Mitchell F, eds. American becoming: racial trends and their consequences. Washington: National Academy of Sciences Press: 391-434.
National Center for Health Statistics (2004).

Health, United States, 2004 with chartbook on

Trends in the Health of Americans. Hyattsville, MD: NCHS.

Siqueira LM, Rolnitzky LM, Rickert VI (2001). Smoking cessation in adolescents: the role of nicotine dependence, stress, and coping methods. Arch Pediatr Adolesc Med 155: 489-95.

Todd M (2004). Daily processes in stress and smoking: effects of negative events, nicotine dependence, and gender. Psychol Addict Behav 18: 31-9.

Williams DR (1998). African-American health: the role of the social environment. J Urban Health 75: 300-21.

Williams DR (1999). Race, socioeconomic status, and health: the added effects of racism and discrimination. Ann New York Acad Sci 896: 173-88.

Williams DR, Collins C (1995). US socioeconomic and racial differences in health: patterns and explanations. Ann Rev Sociol 21: 349-386.

Wills TA, Sandy JM, Yaeger AM (2002). Stress and smoking in adolescence: a test of directional hypotheses. Health Psychol 21: 122-30.

\section{Acknowledgments}

This research was supported by the NIDCR research grant K22DE15317 and the Robert Wood Johnson Health and Society Scholar Program.

Address for correspondence

Luisa N. Borrell, DDS, PhD

Assistant Professor

Department of Epidemiology

Mailman School of Public Health

Columbia University

722 West $168^{\text {th }}$ Street, $16^{\text {th }}$ Floor Room 1611

New York, N.Y. 10032

USA

Tel.: +1-212-305-9339

Fax: +1-212-342-0148

e-mail: Inb2@columbia.edu 